\title{
The Difference of Clinical Symptoms and Audiovestibular Function between Intrameatal and Extrameatal Acoustic Neuroma
}

\author{
Jeong Yeop Lee, Se A Lee, Sang Kuk Lee, Jeong Tae Kim, \\ Seung Bum Park, Bo Gyung Kim, and Jong Dae Lee \\ Department of Otorhinolaryngology-Head and Neck Surgery, Soonchunhyang University College of Medicine, Bucheon, Korea
}

\author{
청신경종양 환자에서 종양의 크기에 따른 임상양상, 청력 및 전정기능검사의 비교 \\ 이정엽 · 이세아 · 이상국 · 김정태 · 박승범 · 김보경 · 이종대 \\ 순천향대학교 의과대학 이비인후과학교실
}

\author{
Received January 8, 2016 \\ Revised February 22, 2016 \\ Accepted February 29, 2016 \\ Address for correspondence \\ Jong Dae Lee, MD, PhD \\ Department of Otorhinolaryngology- \\ Head and Neck Surgery, \\ Soonchunhyang University \\ College of Medicine, \\ 170 Jomaru-ro, Wonmi-gu, \\ Bucheon 14584, Korea \\ Tel $+82-32-621-5451$ \\ Fax $+82-32-621-5016$ \\ E-mail1jdent@schmc.ac.kr
}

\begin{abstract}
Background and Objectives Various hearing tests and vestibular function tests are used to diagnose acoustic neuroma. We analyzed the clinical characteristics and the results of audiovestibular function tests between patients of intrameatal and extrameatal acoustic neuroma. Subjects and Method Reviewing the medical records for 64 patients with acoustic neuroma between March 2007 and February 2014, we divided the patients into two groups, intrameatal (31 patients) and extrameatal acoustic neuroma (33 patients) according to the involvement of cerebropontine angle. We compared the clinical characteristics, pure tone audiograms, speech audiometry, caloric test, and vestibular evoked myogenic potential (VEMP) between the two groups.

Results While hearing loss was the most frequent presenting symptom in patients with intrameatal acoustic neuroma, dizziness was the most common symptom in patients with extrameatal acoustic neuroma. Hearing thresholds measured by pure tone audiometry and speech discrimination scores were significantly worse for patients with extrameatal acoustic neuroma. Abnormal unilateral canal paresis of caloric test was significantly higher for extrameatal acoustic neuroma than for intrameatal acoustic neuroma. Most patients with acoustic neuroma showed abnormal findings in the VEMP test, but the number of patients between intrameatal and extrameatal acoustic neuroma did not differ significantly.

Conclusion Clinical symptoms and the results of audiovestibular function tests differed according to the tumor size of acoustic neuroma. Physicians should counsel patients presenting with audiovestibular symptoms of the possibility of acoustic neuroma.
\end{abstract}

Korean J Otorhinolaryngol-Head Neck Surg 2016;59(5):361-5

Key Words Acoustic neuroma $\cdot$ Extrameatal $\cdot$ Hearing $\cdot$ Intrameatal $\cdot$ Vestibular.

\section{서 론}

청신경종양(vestibular schwannoma)은 8번째 뇌신경의 전 정신경분지에서 생기는 양성 신경초종으로 두개내 종양의

8 $10 \%$ 정도를 차지하고 있고, 소뇌교각에 발생하는 종양 중 에서는 약 $90 \%$ 정도로 많은 빈도를 보인다.,2) 임상적으로 매
년 10만 명당 1 명 꼴로 발생한다고 알려져 있으나," 최근 자기 공명영상(magnetic resonance imaging)의 발달과 광범위한 사용으로 매우 작은 청신경종양도 진단되고 있어 발생률은 점점 높아지고 있다. ${ }^{4}$

청신경종양은 순음청력검사 및 어음청력검사로 후미로성 병변을 의심할 수 있고, 청성뇌간반응(auditory brainstem res- 
ponse)검사가 선별검사로 많이 사용되어 왔다. 전정기능검사의 진단적 의미는 거의 없으나, 온도안진검사(caloric test)는 청신 경종양을 가진 환자의 전정기능상태를 평가하는 데 유익하며, 하전정신경의 기능을 반영하는 전정유발근전위(vestibular evoked myogenic potential, VEMP)검사는 종양의 기원을 유추 하는 데 사용될 수 있으나 현재까지는 논란의 여지가 있다.5)

하지만 국내에서 청신경종양의 크기에 따른 임상양상, 청력 검사 및 전정기능 검사의 차이에 따른 보고는 거의 없어서 크 기에 따른 임상 및 검사에 대한 정보가 부족한 실정이다.) 본 연구에서는 청신경종양의 크기에 따른 임상양상, 청력검사 및 전정기능검사의 특징을 비교 분석해 보고자 하였다.

\section{대상 및 방법}

\section{대 상}

2007년 3월부터 2014년 2월까지 7년간 순천향대학교 부천 병원 이비인후과에서 청신경종양으로 진단받았거나, 타 과에 서 진단받고 이비인후과로 협진의뢰된 환자 64예를 대상으로 후향적 의무기록을 분석하였다. 남녀 비율은 27:37로 여성에 서 약간 많았으며 환자군의 연령은 24세에서 74세까지 다양 하였고 평균연령은 53.5세였다. 환자들을 종양의 크기에 따라 내이도에 국한된 종양군(intrameatal group)과 내이도를 포함 하여 소뇌교각까지 침범한 종양군(extrameatal group)으로 나 누었고, 진단 시 처음 촬영한 자기공명영상 중에서 종양의 내 이도 부위가 포함된 가장 큰 직경을 측정하였다. 각 군당 환자 수는 intrameatal group 31명, extrameatal group 33명이었다.

\section{방 법}

청신경종양환자의 주 증상, 처음 측정한 순음청력검사, 어 음청력검사, 청성뇌간반응검사, 온도안진검사, 전정유발근전위 검사 등을 각 군에 따라 분석하였다.

순음청력검사는 $500,1000,2000,4000 \mathrm{~Hz}$ 에 대한 주파 수별 청력손실을 4 분법으로 평균청력역치를 계산하였고, 어 음청력검사는 단음절어를 이용한 어음명료도 검사(speech discrimination score)를 사용하였다. 청성뇌간반응검사는 Navigator pro(Bio-Logic System, Mundelein, IL, USA)를 이용하였고, 자극음은 $90 \mathrm{~dB} n \mathrm{~nL}$ 의 클릭음으로 파형에 따 른 잠복기를 측정하였다. 양측 $\mathrm{V}$ 파의 잠복기 차이(interaural latency difference)가 $0.2 \mathrm{~ms}$ 미만일 때를 정상으로 하고, $0.2 \mathrm{~ms}$ 이상일 때를 지연, 파형이 없을 때를 무반응으로 하 였고 지연과 무반응을 비정상으로 해석하였다. ${ }^{7)}$

온도안진검사는 환자를 $60^{\circ}$ 눕힌 상태에서 외이도에 섭씨 $24^{\circ} \mathrm{C}$ 와 $50^{\circ} \mathrm{C}$ 의 공기로 1 분간 온도자극을 주었으며 Jonkee 공
식을 이용하여 반고리관 마비를 계산하였다. 반고리관 마비 (canal paresis)가 25\% 이하를 정상, 초과하였을 때를 비정상 으로 해석하였다.

경부전정유발근전위(cervial VEMP, cVEMP)는 $90 \mathrm{~dB}$ 의 클릭음을 헤드폰으로 자극하였고, $\mathrm{p} 13$ 과 $\mathrm{n} 23$ 의 잠복기와 진 폭차의 비를 구하여 본원 검사실 정상치와 비교하였다. 파형 이 없거나 양이 진폭차의 비(VEMP asymmetry)가 27.7을 초 과했거나, p13의 잠복기가 $15.07 \mathrm{msec}$ 을 초과했을 때 비정상 으로 하였다. ${ }^{8)}$

통계는 SPSS version 20.0(SPSS Inc., Chicago, IL, USA) 프로그램을 이용하여 두 군 간의 청력검사는 Mann-Whitney $\mathrm{U}$ test, 두 군 간의 온도안진검사와 전정유발근전위는 Fischer's exact test를 통해 검증을 하였다. 통계학적 유의수준은 $p$ value 0.05 미만으로 하였다.

\section{결 과}

\section{환자군 통계와 임상적 주증상}

Intrameatal group과 extrameatal group 간의 나이, 성별, 좌우측 간 차이는 없었다. Intrameatal group의 종양의 크기 는 $3.7 \mathrm{~mm}$ 에서 $13.3 \mathrm{~mm}$ 로 평균 $8.58 \mathrm{~mm}$ 였고, extrameatal group의 종양의 크기는 $13.5 \mathrm{~mm}$ 에서 $54.4 \mathrm{~mm}$ 로 평균 27.64 $\mathrm{mm}$ 였다. 총 31명의 intrameatal group 중에서 청력소실이 가 장 흔한 증상으로 14명(45.2\%)이 호소하였고 그중에서 돌발성 난청은 5명(16.1\%)이었다. 기타 어지럼(8명, 25.8\%), 이명(7명, $22.6 \%$ ), 이충만감(1명), 우연히 발견된 1명 순이었다. 총 33명의 extrameatal group에서는 어지럼이 14명(42.4\%)으로 가장 흔 한 증상이었다. 청력소실은 13 명(39.4\%)으로, 그중에서 돌발성 난청은 4명(12.1\%)이었다. 기타 이명(4명, 12.1\%), 두통(2명, $6.1 \%$ ) 순이었다(Table 1).

\section{청력검사}

순음청력검사의 청력역치는 intrameatal group에서 중간 값이 $53.8 \mathrm{~dB}(6.3 \sim 103)$ 이었고 extrameatal group에서 중간 값이 $70.6 \mathrm{~dB}(25 \sim 120)$ 로 extrameatal group에서 의의있게 더 높은 청력역치를 보였다(Table 2). 건측의 청력역치는 intrameatal group과 extrameatal group에서 중간값이 각각 $16.3 \mathrm{~dB}(1.3 \sim 98.8), 15.6 \mathrm{~dB}(5 \sim 87.6)$ 로 차이를 보이지 않았다.

어음명료도는 intrameatal group에서 중간값이 48\%(0 96) 였고 extrameatal group에서 중간값이 22\%(0 100)로 extrameatal group에서 의의있게 더 낮은 어음명료도를 보였다(Table 2).

총 38 명의 환자에서 시행된 청성뇌간반응검사에서는 intrameatal group(n=22) 중에 7명(31.8\%)에서 정상소견이었으 
Table 1. The demographics and chief complaint

\begin{tabular}{lccc}
\hline & Intrameatal group $(\mathrm{n}=31)$ & Extrameatal group $(\mathrm{n}=33)$ & $\mathrm{p}$-value \\
\hline Age $(\mathrm{yrs})$ & $54.4 \pm 14.1$ & $52.7 \pm 12.9$ & 0.613 \\
Gender $(\mathrm{M}: \mathrm{F})$ & $14: 17$ & $13: 20$ & 0.641 \\
Tumor side $(\mathrm{R}: \mathrm{L})$ & $15: 16$ & $15: 18$ & 0.814 \\
Chief complaint & & & \\
$\quad$ Hearing disturbance & 14 (sudden 5) & 13 (sudden 4) & 14 \\
Dizziness & 8 & 4 & Headache 2 \\
Tinnitus & 7 & Earfullness 1, incidental 1 & \\
Others & &
\end{tabular}

Table 2. The difference of pure tone audiometry and speech discrimination score between intrameatal group and extrameatal group

\begin{tabular}{|c|c|c|c|}
\hline & Intrameatal group $(n=31)$ & Extrameatal group $(n=33)$ & $p$-value \\
\hline Pure tone audiometry threshold (dB) & $53.8(6.3-103)$ & $70.6(25-120)$ & 0.012 \\
\hline $0-20$ & 3 & 0 & \\
\hline $21-30$ & 5 & 3 & \\
\hline $31-40$ & 3 & 3 & \\
\hline $41-60$ & 11 & 9 & \\
\hline $61-80$ & 7 & 4 & \\
\hline$>81$ & 2 & 14 & \\
\hline Speech discrimination score (\%) & $48(0-96)$ & $22(0-100)$ & 0.045 \\
\hline $100-80$ & 9 & 3 & \\
\hline $79-70$ & 2 & 3 & \\
\hline $69-60$ & 1 & 1 & \\
\hline $59-50$ & 2 & 0 & \\
\hline $49-40$ & 4 & 4 & \\
\hline $39-0$ & 13 & 22 & \\
\hline
\end{tabular}

Table 3. The difference of auditory brainstem response (ABR) between intrameatal group and extrameatal group

\begin{tabular}{lcc}
\hline & $\begin{array}{c}\text { Intrameatal group } \\
(\mathrm{n}=22)\end{array}$ & $\begin{array}{c}\text { Extrameatal group } \\
(\mathrm{n}=16)\end{array}$ \\
\hline ABR & & \\
Normal & 7 & 0 \\
Abnormal & & \\
$\quad$ Delay & 13 & 5 \\
No response & 2 & 11 \\
\hline
\end{tabular}

Table 4. The difference of caloric test between intrameatal group and extrameatal group $(p=0.011)$

\begin{tabular}{lcc}
\hline & \multicolumn{2}{c}{ Caloric test } \\
\cline { 2 - 3 } & Normal & Abnormal \\
\hline Intrameatal group $(\mathrm{n}=31)$ & 15 & 16 \\
Extrameatal group $(\mathrm{n}=26)$ & 4 & 22 \\
\hline
\end{tabular}

며, 잠복기 지연을 보인 경우가 13명(59.1\%)으로 가장 많았다. 하지만 extrameatal group $(\mathrm{n}=16)$ 에서는 모두 무반응 또는 잠 복기지연의 비정상 소견을 보였으며 무반응이 11명(68.8\%)으 로 가장 많았다(Table 3).

\section{전정기능검사}

총 57명의 환자에서 시행된 온도안진검사에서 intrameatal
Table 5. The difference of cervical vestibular evoked myogenic potential (cVEMP) between intrameatal group and extrameatal group $(p=0.283)$

\begin{tabular}{lcc}
\hline & \multicolumn{2}{c}{ cVEMP } \\
\cline { 2 - 3 } & Normal & Abnormal \\
\hline Intrameatal group $(n=28)$ & 8 & 20 \\
Extrameatal group $(n=16)$ & 2 & 14 \\
\hline
\end{tabular}

$\operatorname{group}(\mathrm{n}=31)$ 에서는 반고리관마비소견이 16 명(51.6\%)이고 extrameatal group $(\mathrm{n}=26)$ 에서는 반고리관마비소견이 22명(84.6\%) 으로 extrameatal group에서 유의하게 높은 반고리관마비소 견을 보였다(Table 4).

총 44명의 환자에서 시행된 전정유발근전위검사에서는 intrameatal group $(\mathrm{n}=28)$ 에서 비정상소견이 20명(71.4\%)이고 extrameatal group $(\mathrm{n}=16)$ 에서는 비정상소견이 14 명 $(87.5 \%)$ 이 었으나 두 군 간의 유의한 차이는 없었다(Table 5).

\section{고 찰}

청신경종양의 크기 분류는 오랫동안 여러 저자에 따라 다 양하게 사용되어 왔으나, 2001년 Consensus Meeting on Systems for Reporting Results in Acoustic Neuroma에서 종양 
을 크게 intrametal 종양과 extrameatal 종양으로 분류하였 고, extrameatal 종양은 다시 크기에 따라 grade 1(1 10 mm), grade 2(11 20 mm), grade 3(21 30), grade 4(31 40), grade $5(>40 \mathrm{~mm})$ 로 세분하였다. ${ }^{9)}$ 본 연구에서도 청신경종양을 intrameatal group과 extrameatal group으로 나누었으나 증례 수의 차이를 최소화하고 대상자 수를 많게 설정하기 위해 extrameatal group 종양은 세분하지 않았다.

청신경종양은 크기가 작을수록 수술 후의 예후가 좋아, ${ }^{10)}$ 청신경종양의 조기 진단이 매우 중요하다고 할 수 있다. 청신 경종양에서 나타나는 이과적 증상은 환측의 난청이 가장 많 고 그 외에 어지럼, 이명 등이 흔한 증상이며, ${ }^{11,12)}$ 돌발성 난청 은 7 20\%에서 호소하는 증상으로 알려져 있다. ${ }^{13)}$ 본 연구에 서도 환자들은 난청, 어지럼 및 이명 등을 주 증상으로 호소 하여 내원하였다. 난청을 주 증상으로 보인 빈도는 intrameatal group에서 extrameatal group보다 약간 높게 나타났는데 이 는 extrameatal group의 대부분의 환자에서 난청이 동반되어 있었지만 병원에 내원한 주 증상은 어지럼인 경우가 많았기 때문인 것으로 판단된다. 돌발성 난청이 주 증상인 경우도 intrameatal group과 extrameatal group에서 각각 $16.1 \%$ 와 $12.1 \%$ 로 나타나서 기존 보고와 비슷하였다.

청신경종양에서 청력검사는 가장 기본적인 검사로, 진단적 가치 외에도 치료를 결정하는 데 중요한 역할을 한다. 종양의 크기와 난청의 정도는 크게 차이가 없다는 보고가 많고, 최근 국내연구에서도 종양의 크기에 따른 청력검사의 차이가 없음 을 보고하였으나 ${ }^{14)}$ 본 연구에서는 intrameatal group에 비해 extrameatal group이 의의 있게 청력이 악화된 소견을 보였다. 이는 intrameatal group에서 청력이 정상인 데도 불구하고 조 기에 진단이 되었기 때문에 나온 결과로 해석할 수도 있다. 청 성뇌간반응검사는 자기공명영상이 청신경종양의 표준화된 검 사가 되기 전까지는 선별검사로 이용되어 왔으나, $1 \mathrm{~cm}$ 보다 작은 종양에서는 민감도가 떨어져서 진단적 한계가 있다. ${ }^{15)}$ 본 연구의 결과에서도 intrameatal group에서 청성뇌간반응의 민감도는 $68.2 \%$ 로 낮게 측정되었고 파형의 손실보다는 잠복 기 지연이 흔하게 나타나 청신경종양이 작은 경우에 검사를 해석할 때 주의를 요한다. 청신경종양에서 청력은 종양의 크 기 이외에 내이도 기저부(fundus)의 침범여부에 따라 영향을 받을 수도 있으나 본 연구에서는 고려하지 않았다.

청신경종양에서 전정기능검사는 진단적 가치보다는 주로 환자의 전정기능을 평가하기 위해 사용되어 왔다. 또한 온도안 진검사는 주로 외측반고리관의 기능을 보는 검사로 상전정신 경의 기능을 반영하고, ${ }^{16)}$ 경부전정유발근전위검사는 자극음 이 구형낭을 자극하고 구심성 경로인 하전정신경의 기능을 반 영한다. ${ }^{4)}$ 온도안진검사는 종양의 크기가 커짐에 따라 반고리
관 마비정도도 커지는데, ${ }^{17)}$ 본 연구에서도 extrameatal group 이 반고리관 마비를 보인 빈도가 intrameatal group에 비해 높 게 나왔다. 하지만 경부전정유발근전위검사는 양측 group에 서 비정상을 보인 빈도가 각각 $71.4 \%, 87.5 \%$ 로 비교적 높게 나 타냈다. 이는 청신경종양이 주로 하전정신경에서 기원하므로 하전정신경의 기능을 반영하는 경부전정유발근전위검사의 기 능이상이 초기에 비정상을 보인다고 생각한다.

본 연구의 한계점으로는 후향적 연구로 인하여 대상환자에 서 모든 검사가 이루어지지 않은 것과 증례수가 많지 않아서 extrameatal group을 세분하여 분류하지 못하였다는 점이 있 다. 또한 intrameatal group의 경우 수술적 치료보다는 경과 관찰을 주로 시행하여서 종양의 기원과 전정기능검사의 상관 관계를 알 수 없었다는 점도 있다.

본 연구에서 청각증상은 청신경종양의 크기에 상관없이 비 슷하게 흔한 증상이었으나 어지럼은 큰 종양에서 주로 호소하 였다. 또한 내이도에 국한된 청신경종양은 청성뇌간반응에서 약 $30 \%$ 가 정상이고 온도안진검사에서 약 $50 \%$ 에서 정상을 보 일 수 있다는 것을 보여주고 있다. 따라서 청신경종양은 일측 난청, 이명 및 어지럼 등의 이과적 증상을 보이는 환자에서 항 상 의심해 봐야 하는 질환으로 판단된다.

\section{REFERENCES}

1) Møller MN, Hansen S, Caye-Thomasen P. Peripheral vestibular system disease in vestibular schwannomas: a human temporal bone study. Otol Neurotol 2015;36(9):1547-53.

2) Brackmann DE, Arriaga MA. Neoplasms of the Postierior Fossa. In: Flint PW, Haughey BH, Lund VJ, Niparko JK, Richardson MA, Thomas Robbins K, et al., editors. Cummings OtolaryngologyHead and Neck surgery. 5th ed. Philadelphia, PA: Mosby/Elsevier; 2010. p.2514-41.

3) Kshettry VR, Hsieh JK, Ostrom QT, Kruchko C, Barnholtz-Sloan JS. Incidence of vestibular schwannomas in the United States. J Neurooncol 2015;124(2):223-8.

4) Chae SW, Kim MG, Choi JH, Hwang SJ. MRI technique for the detection of acoutic neuroma. Korean J Otolaryngol-Head Neck Surg 2000;43(5):488-92.

5) Murofushi T, Halmagyi GM, Yavor RA, Colebatch JG. Absent vestibular evoked myogenic potentials in vestibular neurolabyrinthitis. An indicator of inferior vestibular nerve involvement? Arch Otolaryngol Head Neck Surg 1996;122(8):845-8.

6) Park KH, Choung YH, Kim CH, Lee WS. Clinical evaluation of small vestibular schwannoma. Korean J Otolaryngol-Head Neck Surg 2004;47(1):22-6.

7) Park K, Chun YM, Park HJ, Lee DH. Decision analysis in diagnosis of small acoustic tumors. Korean J Otolaryngol-Head Neck Surg 1999; 42(1):22-8

8) Lee JD, Park MK, Lee BD, Park JY, Lee TK, Sung KB. Otolith function in patients with head trauma. Eur Arch Otorhinolaryngol 2011;268(10):1427-30.

9) Kanzaki J, Tos M, Sanna M, Moffat DA, Monsell EM, Berliner KI. New and modified reporting systems from the consensus meeting on systems for reporting results in vestibular schwannoma. Otol Neurotol 2003;24(4):642-8; discussion 648-9.

10) Glasscock ME 3rd, Hays JW, Minor LB, Haynes DS, Carrasco 
VN. Preservation of hearing in surgery for acoustic neuromas. J Neurosurg 1993;78(6):864-70.

11) Lee SH, Choi SK, Lim YJ, Chung HY, Yeo JH, Na SY, et al. Otologic manifestations of acoustic neuroma. Acta Otolaryngol 2015;135(2): 140-6.

12) Kentala E, Pyykkö I. Clinical picture of vestibular schwannoma. Auris Nasus Larynx 2001;28(1):15-22.

13) Lee JD, Lee BD, Hwang SC. Vestibular schwannoma in patients with sudden sensorineural hearing loss. Skull Base 2011;21(2):75-8.

14) Choung YH, Park K, Shin Y, Lee J, Lee WS, Choi HS. Clinical characteristics of vestibular schwannoma presenting as sudden hearing loss. J Clinical Otolaryngol 2005;16:54-9.

15) Ruckenstein MJ, Cueva RA, Morrison DH, Press G. A prospective study of ABR and MRI in the screening for vestibular schwannomas. Am J Otol 1996;17(2):317-20.

16) Sando I, Black FO, Hemenway WG. Spatial distribution of vestibular nerve in internal auditory canal. Ann Otol Rhinol Laryngol 1972; 81(3):305-14.

17) Tringali S, Charpiot A, Ould MB, Dubreuil C, Ferber-Viart C. Characteristics of 629 vestibular schwannomas according to preoperative caloric responses. Otol Neurotol 2010;31(3):467-72. 